\title{
INTELECTUAIS E OPINIÃO
}

THAÍS MANHÃES ALVES SOARES UNIVERSIDADE FEDERAL DE JUIZ DE FORA JUIZ DE FORA, MINAS GERAIS, BRASIL THAISMANHAESALVES@GMAIL.COM

PAULO ROBERTO FIGUEIRA LEAL UNIVERSIDADE FEDERAL DE JUIZ DE FORA JUIZ DE FORA, MINAS GERAIS, BRASIL PABETO.FIGUEIRA@UOL.COM.BR 


\section{INTELECTUAIS E OPINIÃO}

Resumo: A partir do artigo "Política externa e opinião: a imprensa no debate nacional”, de autoria própria, busca-se o aprofundamento sobre o tema da influência dos intelectuais sobre as discussões políticas publicadas nos periódicos. No caso da pesquisa em questão, foi analisado o caderno "Opinião" do jornal O Globo. Assim, cabe apuração do papel dos intelectuais nesse meio, sendo necessária prévia revisão bibliográfica no sentido de embasar as ideias a respeito das definições de intelectual, de suas funções e também de seu papel histórico nas sociedades. O objeto a ser analisado consiste nos artigos opinativos analisados na pesquisa prévia já citada, de autoria de quatro distintos intelectuais convidados pelo jornal O Globo, assim como seus perfis. Conclui-se que a atividade intelectual é historicamente determinada, e a trajetória de vida de cada personalidade explica as opiniões defendidas por estes.

Palavras Chave: Intelectuais; Opinião; O Globo

\section{INTELECTUALES Y OPINIÓN}

Resumen: A partir del artículo "Política exterior y opinión: la prensa en el debate nacional", de autoría propia, se busca la profundización sobre el tema de la influencia de los intelectuales sobre las discusiones políticas publicadas en los periódicos. En el caso de la investigación en cuestión, se analizó el cuaderno "Opinión" del diario O Globo. Así, cabe constatar el papel de los intelectuales en ese medio, siendo necesaria previa revisión bibliográfica en el sentido de basar las ideas acerca de las definiciones de intelectual, de sus funciones y también de su papel histórico en las sociedades. El objeto a ser analizado consiste en los artículos opinativos analizados en la investigación previa ya citada, de autoría de cuatro distintos intelectuales invitados por el diario O Globo, así como sus perfiles. Se concluye que la actividad intelectual es históricamente determinada, y la trayectoria de vida de cada personalidad explica las opiniones defendidas por éstos.

Palabras Clave: Intelectuales; Opinión; O Globo

\section{INTELLECTUALS AND OPINION}

Abstract: Following the article "Foreign policy and opinion: the press in the national debate", of this own author, it is sought the deepening on the subject of the influence of intellectuals on the political discussions published in newspapers. In the case of the research in question, the "Opinião" section of the O Globo newspaper was analyzed. Thus, the role of intellectuals in this area ought to be investigated, and a previous bibliographical revision is necessary in order to base ideas on the definitions of what is a intellectual, what are their functions and also their historical role in societies. The object 
to be analyzed consists of the opinion articles analyzed in the previous research already cited, written by four distinguished intellectuals invited by the newspaper O Globo, as well as their profiles. It is concluded that intellectual activity is historically determined, and the life trajectory of each personality explains the opinions defended by them.

Key-word: Intellectuals; Opinion; O Globo

\section{INTRODUÇÃO}

O papel dos intelectuais, em qualquer sociedade, incita a discussão não somente sobre o objeto político em questão, mas também sobre o próprio dever ser do intelectual, isto é, sua função dentro da coletividade. Tal indagação surge numerosa e natural, sendo próprio do seu ofício o questionamento de tudo, inclusive de si próprio. Talvez seja por isso, supõe Bobbio, que existam tantos trabalhos dedicados à busca de uma definição e à análise do papel destes que se colocam como os produtores e propagadores das ideias e sentidos em nossas sociedades. Apesar de existirem ao longo da história de todas as sociedades (antigas e modernas), a noção de uma classe de intelectuais é muito mais recente, e tem se consolidado a partir do século XIX, quando a grande repercussão do caso Dreyfus ${ }^{1}$ levou os franceses a questionarem o papel destes pensadores no desenrolar social e político do país. Deste então, a influência política e cultural dos intelectuais tem suscitado intensos debates e extensas produções acadêmicas, algumas das quais utilizaremos aqui para embasar nossa análise.

Primeiramente cabe analisar a definição do que é ser um intelectual, ou melhor, as definições, já que são estas tão numerosas que seria impossível aqui abarcar todas as existentes. A definição com a qual trabalharemos vem do italiano Noberto Bobbio, que os define como "alguém que não faz coisas, mas reflete sobre coisas; que não maneja objetos, mas símbolos; alguém cujos instrumentos de trabalho não são máquinas, mas ideias" (BOBBIO, 1997, p. 68). Para o autor, o simples fato de alguém escrever sobre intelectuais já torna o próprio um intelectual, mesmo que esteja declarando que estes não existam ou que estejam todos mortos. Justamente por ser este seu ofício, o de escrever sobre os demais assuntos, acaba que sejam os

1 SUZANO, Milene. “J'accuse” na imprensa brasileira: algumas repercussões e interpretações do caso Dreyfus.Escritos. Revista da Fundação Casa de Rui Barbosa. Ano 2, n. 2, 2008. 
próprios intelectuais os maiores produtores de análises sobre eles mesmos. Talvez seja por isso que o debate em si sobre os intelectuais seja uma discussão eterna, sem tréguas.

São também vastos os trabalhos de auto repreensão. Se cobram demasiadamente por falarem demais, ao mesmo tempo que também se cobram, em algumas situações, por falarem de menos. Segundo Bobbio, a maior parte destes discursos está viciada por um erro bastante conhecido: a falsa generalização. Falar dos intelectuais como se fossem uma classe homogênea é uma falha bastante recorrente, pautada em estereótipos que visam não o conhecimento, mas o convencimento daquele que lê (BOBBIO, 1997). Dessa forma, é impossível encontrar uma definição específica o suficiente que permita se fazer qualquer tipo de juízo de valor sobre o intelectual. Nesse caso, é suficiente o apontamento de algumas definições existentes sobre o seu ofício, assim como suas funções na sociedade e seu papel histórico.

Bobbio, a partir de sua definição, cria uma divisão dos intelectuais entre duas categorias: os ideólogos e os expertos. Tal distinção pretende ser objetiva, e não subjetiva, no sentido de que cada tipo desenvolve uma função diversa com relação à dimensão política, tema fundamental para o autor. Assim, os chamados intelectuais ideólogos seriam, para ele, aqueles responsáveis pelo fornecimento dos princípios-guia de uma coletividade, isto é, a elaboração das ideias em seu estado puro; enquanto os intelectuais expertos seriam os transmissores dessas mesmas ideias, fornecedores do conhecimento meio, isto é, o conhecimento mais técnico (BOBBIO, 1997). Com isto, em uma forma de simplificar a questão, podemos dizer que Bobbio cria uma distinção entre aqueles responsáveis por pensar soluções e aqueles responsáveis por implementar tais soluções.

Gramsci, autor fundamental na discussão sobre intelectuais, também cria para si uma distinção dentre o grupo. Separa-os entre os ditos intelectuais orgânicos e os tradicionais. Os primeiros, segundo o autor, são aqueles que se mantêm vinculados à sua classe social de origem, mantendo-se fiel a esta ao vocalizar e trabalhar por seus interesses; os tradicionais, por outro lado, são aqueles que se filiam a outra classe, e passam a defender os interesses desse novo grupo. É possível citar, como exemplos, os proletários, como intelectuais orgânicos, que defendem a ideologia de sua própria classe, e os clérigos ou militares, como intelectuais tradicionais, que se vincularam a um novo grupo, no caso a Igreja ou o serviço militar, e passaram a trabalhar em prol da nova classe à qual pertencem. 
Ao colocar-se a questão de se constituiriam os intelectuais uma classe autônoma e independente ou se cada classe social possuiria sua própria camada de intelectuais, Gramsci chega à conclusão de que todo grupo social cria para si, organicamente, uma ou mais camadas de intelectuais que lhe dão homogeneidade e consciência da própria função, tendo em vista as necessidades de expansão da própria classe. Assim, para ele, todo grupo que se desenvolve no sentido de dominação e hegemonia trabalha no sentido de uma conquista que seja também ideológica, sendo esta tão mais rápida e eficaz quanto mais o grupo em questão for capaz de elaborar simultaneamente seus próprios intelectuais orgânicos (GRAMSCI, 2001). Com isso, o autor busca também discorrer demasiadamente sobre a educação e, principalmente, a escola, pois considera esta o principal instrumento para a elaboração de intelectuais de diversos níveis.

Em um diálogo com Gramsci, Bobbio também afirma que a ele parece que todos nós, pelo fato de vivermos em uma sociedade de cujas lutas participamos, podemos ser considerados intelectuais orgânicos, "no sentido de que somos portadores de certos valores contra outros, defendemos certos interesses contra outros" (BOBBIO, 1997, p. 87). Assim, ambos os autores defendem uma definição bastante abrangente do que é ser intelectual, pois compartilham a ideia de que todos os seres humanos têm em si um filósofo, um pensador. Para Gramsci, é possível dizer que "todos os homens são intelectuais, mas nem todos os homens têm a função de intelectuais" (GRAMSCl, 2001, p. 18). Aí estaria, portanto, a diferenciação entre aqueles que exercem tal função, isto é, de se ocupar de pensar ideias e difundí-las, carregando tal tarefa como um ofício, e aqueles que o fazem periodicamente, pois a condição humana nos leva a refletir sobre nós mesmos e tudo aquilo à nossa volta. Assim formam-se historicamente, segundo Gramsci, categorias especializadas para o exercício da função de intelectual, sobretudo aquelas ligadas às classes sociais mais importantes. É portanto de suma importância remarcar que "a elaboração das camadas intelectuais na realidade concreta não ocorre num terreno democrático abstrato, mas segundo processos históricos tradicionais muito concretos" (GRAMSCI, 2001, p. 20).

Sendo assim, o que se denomina intelectuais atualmente é o que, em outros tempos, foi chamado de sábio, filósofo ou clérigo, entre outros nomes. Assim, apesar de a palavra intelectual ter se difundido a partir do século XIX com o já citado caso Dreyfus, estes sempre existiram e sempre exerceram importante função em todas as civilizações. Isto porque, em todas as socie- 
dades conhecidas, o poder ideológico sempre esteve presente como fator fundamental não só para a conquista, mas também para a manutenção do domínio e da organização. Desse modo, as ideias e, portanto, seus elaboradores e propagandistas sempre gozaram de grande importância.

Embora com nomes diversos, os intelectuais sempre existiram, pois sempre existiu em todas as sociedades, ao lado do poder econômico e do poder político, o poder ideológico, que se exerce não sobre os corpos como o poder político, jamais separado do poder militar, não sobre a posse de bens materiais, dos quais se necessita para viver e sobreviver, como o poder econômico, mas sobre as mentes pela produção e transmissão de ideias, de símbolos, de visões do mundo, de ensinamentos práticos, mediante o uso da palavra (BOBBIO, 1997, p. 11)

Assim, cada sociedade possui seus próprios detentores do poder ideológico, cuja função muda de acordo com a sua relação com os detentores dos demais poderes. Para Gramsci, os “intelectuais são os 'prepostos' do grupo dominante para o exercício das funções subalternas da hegemonia social e do governo político" (GRAMSCI, 2001, p. 21). Dessa forma, existem sociedades onde tal poder é monopólio de uma só classe, e outras onde este é irradiado a partir de diversos grupos, como é o caso da democracia. Para Bobbio, nestas sociedades o desaparecimento dos intelectuais é bastante improvável pois, fechando-se um canal por onde passava o fluxo do poder ideológico, imediatamente abre-se outro ou outros. Considerando-se a realidade atual, seu desaparecimento torna-se mais improvável visto o número de canais disponíveis à propagação de ideias e manifestações. Assim, os meios de comunicação disponíveis hoje permitem uma maior propagação dos variados fluxos de poder ideológico, tanto no nível local quanto no nível global. No entanto, não é possível afirmar que houve também um aumento igual do seu poder, pois isto diz respeito à não simétrica relação entre poder ideológico e poder político, a qual varia de acordo com as circunstâncias do momento (BOBBIO, 1997).

\section{OS INTELECTUAIS NO BRASIL}

A partir da argumentação de Bobbio, podemos reduzir o nível de análise para o caso brasileiro. É certo que a redemocratização a partir dos anos 1980 permitiu que se criasse um ambiente propício ao florescimento da atividade intelectual, aqui dando destaque à possibilidade de se publicizar 
opiniões das mais diversas em relação não somente à política, mas também à economia, costumes, entre outros. Associado ao boom tecnológico que levou à consolidação da rede mundial de telecomunicações, mais especificamente a internet, cria-se assim um ambiente extremamente favorável à livre circulação de ideias e informações, a qual favorece demasiadamente o ofício do intelectual. Temos portanto um cenário, como cita Bobbio, onde os fluxos de poder ideológico partem de diversas fontes, e são capazes de atingir os mais variados grupos sociais da coletividade. Nesse sentido, torna-se necessária a análise do papel do intelectual nessa sociedade interconectada, através de uma investigação acerca da sua influência sobre os debates publicizados pelos veículos comunicacionais.

As últimas décadas do século XX e o início do século XXI testemunharam o desenvolvimento do que Gramsci denomina sociedade civil, um espaço onde organismos, instituições e indivíduos se relacionam, buscando espaço para suas pautas e opiniões, como uma complementação à ação estatal. Segundo Coutinho, Gramsci vê como um trunfo do liberalismo a criação dos chamados "aparelhos privados de hegemonia", que se consolidam no sentido de fazer frente ao antigo aparelhamento, isto é, a Igreja e o Estado. Essas novas organizações, que se converteram em sindicatos, partidos e jornais, acabam por intensificar as lutas sociais dentro dessa sociedade civil, a qual se torna arena para a defesa de interesses privados, os tornando assim também portadores de materiais culturais e ideológicos (COUTINHO, 2011).

\begin{abstract}
Vemos assim que a sociedade civil tem, por um lado, uma função social própria: a de garantir (ou de contestar) a legitimidade de uma formação social e de seu Estado, os quais não têm mais legitimidade em si mesmos, carecendo do consenso da sociedade civil para se legitimarem. E, por outro lado, que ela tem uma materialidade social própria: apresenta-se como um conjunto de organismos ou de objetificações sociais, diferentes tanto das objetificações da esfera econômica quanto das objetificações do Estado strictu sensu. (COUTINHO, 2011, p. 16)
\end{abstract}

Com isso, em uma sociedade de formação social do tipo ocidental, a organização da cultura já não é mais algo que resulta direta e unicamente da ingerência do Estado, mas sim da complexa e plural sociedade civil. Essa é portanto uma mudança que atinge diretamente os intelectuais, já que estes já não dependem mais do Estado ou de seu aparelhamento ideológico. Abrem-se possibilidades de articulação com organismos privados, 
onde poderão lutar pela hegemonia política e ideológica do grupo social ao qual pertencem, no seio do universo cultural dessa sociedade. Essa, para Coutinho, pode ser considerada a mais importante acepção da noção gramsciana de intelectual orgânico. Assim, segundo o autor, o sistema educacional torna-se relevante campo de batalha entre as variadas concepções político-ideológicas encontradas na sociedade civil, onde as universidades têm se tornado também um espaço onde é travada a luta de classes (COUTINHO, 2011). Assim, confirma-se a importância do espaço acadêmico como campo de formação de intelectuais e, mais ainda, de disputas ideológicas entre grupos sociais que buscam a hegemonia.

É interessante observar a evolução histórica brasileira, cuja trajetória vai de uma situação de completa ausência de uma sociedade civil (como o era no período colonial) à sua consolidação no presente, como um ambiente fértil e complexo, propício ao surgimento e propagação das mais diversas ideologias. Tudo isso é fruto de um longo processo histórico, que se confunde com a gradual inserção brasileira no sistema capitalista liberal. Antes dependentes dos favores das classes dominantes ou do funcionalismo estatal, os intelectuais agora conseguem se sustentar a partir de seu ofício e de forma independente. $O$ fortalecimento de instituições privadas na luta pelo poder político, econômico e ideológico cria um ambiente plural e convidativo à atividade intelectual, a qual poderá se exercer a favor dos diversos grupos sociais existentes, e não somente das elites como o foi no passado.

O próprio desenvolvimento do capitalismo, ao criar um mercado de força de trabalho intelectual, alterou a situação dos produtores de cultura: a possibilidade de que eles exerçam sua função já não depende do favor pessoal, já não resulta da cooptação. O velho intelectual elitista, prestigiado por possuir cultura, converte-se cada vez mais em trabalhador assalariado. Experimenta agora a necessidade de se organizar, como qualquer outro grupo social, para lutar por seus interesses específicos, entre os quais não se situa apenas a melhoria das condições de trabalho; e, entre essas últimas, ocupa lugar de destaque a sua autonomia enquanto criador. A luta pelo específico articula-se aqui com a luta geral, ou seja, com a luta pela liberdade de expressão, de criação e de crítica, que só podem ser asseguradas plenamente num regime democrático aberto à renovação social. De casta fechada, de corporação de notáveis, os intelectuais passam a ser uma parcela do mundo do trabalho. (COUTINHO, 2011, p. 32)

É necessário então que se compreenda bem a trajetória da intelectua- 
lidade brasileira para que se possa apreender seu status atual na nossa sociedade. A conquista da democracia tornou-se base para o florescimento de uma cultura nacional-popular entre nós, e portanto condição essencial à sobrevivência da atividade intelectual livre. Essa emancipação da sujeição ao regime de favores é algo a se destacar já que, segundo Schwarz, o favor tem sido a nossa mediação quase universal. O homem livre do período coIonial, cuja condição não o incluía no grupo dos escravos nem tampouco dos proprietários, tinha seu acesso à vida social e aos bens dependente materialmente do regime de favores. Assim, o favor torna-se o mecanismo através do qual tal classe se reproduzirá, envolvendo nesse processo a classe dos proprietários. E é no seio dessa relação que se desenvolverá toda a vida ideológica da sociedade brasileira, regida portanto por este mesmo mecanismo (SCHWARZ, 2014).

Sergio Miceli foi capaz de captar as dinâmicas desse regime, expondo o padrão de trocas e de dependência patrimonial que permeia as transações entre os detentores do mando político e aqueles em vias de serem incorporados ao sistema de poder. Ou seja, seu trabalho vem a corroborar a tese de que as dinâmicas de classe têm guiado o destino do intelectual brasileiro desde os primórdios da nação, incorporando à análise as variáveis econômicas e políticas que moldam as alianças e rupturas entre as forças sociais (MICELI, 1979). O autor busca assim expor os princípios de expropriação material que permeiam as relações entre dominantes e dominados, os quais tornam-se possíveis através de instituições que dependem, para isso, do trabalho dos intelectuais. É portanto no âmbito da luta de classes e da concorrência entre os diversos grupos da sociedade civil, os quais disputam também o mercado cultural e ideológico, que se pode compreender a trajetória dos intelectuais na história brasileira, permitindo assim também a compreensão de sua condição atual.

É no âmbito desses mercados _o sistema de ensino, a indústria cultural, o terciário político e cultural, etc. _ que se sucede a legitimação das diferenças sociais, isto é, neles se constitui o valor desigual das formas disponíveis de capital_títulos e diploma, postos e cargos, padrões de gosto, etc. _de que se apropriam os diversos grupos e classes segunda as posições que lhes cabem na estrutura social. Enquanto prevalecer a tendência de enxergar as relações de classe como o confronto entre entidades coletivas movidas por um destino inescapável, cuida-se pouco da heterogeneidade produzida por padrões de diferenciação sutilmente inculcados através 
do sistema escolar, da indústria cultural e das demais instituições que se incubem do trabalho cotidiano de veicular as linguagens que expressam as diferenças sociais sob a capa de diferenças biológicas, escolares, culturais, etc. (MICELI, 1979, p. 196)

O poder ideológico e a dependência se fazem sentir também no âmbito externo. Assim, a história da cultura brasileira pode ser definida como a história da assimilação mecânica ou crítica da cultura universal. Quando isto ocorre, pode-se dizer que determinada camada ou classe social encontrou ou julgou encontrar nessa ideologia a expressão de seus próprios interesses brasileiros de classe (COUTINHO, 2011). Assim, o ritmo de nossa vida ideológica tem sido ditado pela dependência do país em relação aos centros do mercado mundial, com ênfase para a Europa. A adoção de tais ideias não resulta, portanto, do racionalismo, mas sim da relação de dependência cultural, política e econômica do Sul em relação do Norte. Segundo Schwarz, ao longo de sua reprodução social, o Brasil tem incansavelmente adotado ideias europeias, porém sempre em sentido impróprio. Em sua tese acerca das ideias fora do lugar, o autor busca destacar as disparidades entre a sociedade brasileira escravista e o conjunto de ideias liberais burguesas provenientes da Europa, cenário que atestaria a impraticabilidade dessas ideologias em território tupiniquim. Seguindo tal raciocínio, a questão a ser destacada aqui é que a matéria do intelectual é historicamente formada, e registra de algum modo o processo social a que deve sua existência (SCHWARZ, 2014). Sendo assim, as ideias (assim como as relações sociais) no Brasil sempre tiveram como características os contrastes, as desproporções, os disparates, os anacronismos, as contradições e as conciliações, fruto de uma irracional importação de costumes e ideias europeias.

Para Oliven, no entanto, os empréstimos culturais são uma constante em qualquer cultura. Crítico da tese de Schwarz, argumenta que a dinâmica cultural implica um processo de desterritorialização e reterritorialização. Ideias e costumes migram de um lugar para o outro, sendo assim adaptadas a novos contextos e ambientes, onde se transformam, dando origem a novas ideias. Esta seria, portanto, uma das maiores riquezas da dinâmica cultural brasileira, ou seja, sua capacidade de digerir criativamente o que vem de fora, reelaborá-lo e dar cunho próprio ao que transforma, criando assim algo novo (OLIVEN, 2001). Sendo assim, tal capacidade de importação seria um qualidade e não uma deformidade da trajetória intelectual brasileira, traço que se mantém até os dias de hoje. 
Desse modo, após extensa análise, pode-se afirmar que o curso da atividade intelectual no Brasil tem se misturado aos acontecimentos políticos, econômicos e sociais de sua história, os quais foram determinantes para a consolidação do cenário atual de ampla abertura de espaços e fluxos disponíveis aos intelectuais brasileiros de hoje. Assim como sua matéria, a trajetória pessoal destes pensadores é historicamente determinada, cabendo sempre uma análise não só de seus trabalhos, mas também de seus perfis. As determinações de classe têm exercido grande influência sobre o exercício intelectual, como atestam Gramsci, Bobbio, Coutinho e outros, sendo fundamental que se considere, em qualquer análise, as dinâmicas e disputas sociais em que estão inseridos os profissionais a serem analisados, assim como seus perfis, tarefa que buscaremos executar na seção a seguir.

\section{INTELECTUAIS E OPINIÃO}

No artigo intitulado "Política externa e opinião: a imprensa no debate nacional", procurei apontar as tentativas do jornal O Globo de influenciar o debate nacional acerca de uma possível mudança nos rumos da política externa brasileira em relação ao Mercosul. Tal movimento se dá logo quando se inicia o processo de impeachment da então presidente da república Dilma Rousseff (PT), a qual seria então substituída por seu vice, Michel Temer (PMDB). A ascensão de Temer ao mais alto cargo do executivo se deu juntamente a uma guinada no programa de governo, o qual viu a implementação (ou tentativa) de inúmeras reformas e a adoção de políticas decididamente divergentes das praticadas por sua antecessora ${ }^{2}$. Com isso, abriu-se uma janela àqueles que sonhavam com mudanças no relacionamento com nossos vizinhos, com destaque à Venezuela. Defensor de tal ideia, o jornal O Globo pode expressar, através de seus editoriais, a opinião de que era necessário o abandono de um parceiro incômodo, sendo necessário que se voltasse o foco do bloco à questão comercial, matéria de suma importância para o jornal. Para isso, contou com um time de intelectuais cujas posições acerca do assunto foram publicadas em seu caderno de opiniões.

No total, foram selecionados quatro artigos publicados no ano de 2016 por colunistas, autoridades ou convidados do jornal, sendo o restante dos artigos acerca desse assunto publicados no formato de editoriais. Dos qua-

2 http://epocanegocios.globo.com/Economia/noticia/2017/05/um-ano-de-governo-temer-reformas-traicoes-e-uma-economia-que-teima-em-nao-melhorar.html 
tro artigos destacados, apenas um se caracteriza por defender uma opinião contrária à do jornal, sendo o restante dos artigos utilizados de forma a corroborar a tese defendida em seus editoriais. O reduzido número de textos encontrados atestam a pífia cobertura jornalística acerca dos acontecimentos políticos em nosso entorno regional, a qual tem encontrado tímido espaço nos veículos nacionais, cujas matérias comumente se resumem, quando abordam a questão, a cobrir as mazelas venezuelanas e a destacar os desacertos de seu governo. Portanto, é fato que, quando tratam da questão de uma mudança no Mercosul, esses mesmos veículos acabam por insistir no caso venezuelano, forçando a centralização desta pauta nos assuntos relacionados ao bloco.

Cronologicamente, cabe analisar primeiramente a contribuição de Sibá Machado (PT), deputado federal pelo Acre, à época líder de seu partido na Câmara dos Deputados. Geógrafo e ex-agricultor, Machado possui extensa carreira pública, tendo atuado junto a sindicatos, inclusive tendo sido alçado ao posto de presidente da Central Única dos Trabalhadores, onde desempenhou dois mandatos (1991/1994). Apesar de ser natural do Piauí, consolidou sua carreira política no Acre, e tem sido fiel ao Partido dos Trabalhadores, único partido pelo qual já disputou eleições ${ }^{3}$. Tendo participado ativamente dos governos petistas, é natural que Machado adote o posicionamento de defesa da política externa praticada neste período. A sinalização de um movimento pela mudança do curso dessa política lhe confere a oportunidade de publicizar tal argumentação, sendo assim um intelectual a quem o jornal concede espaço para suas alegações.

O artigo de Machado é exposto ao lado do editorial do jornal, cujo letreiro "Nossa opinião" o coloca em clara oposição ao artigo do deputado, definido como "Outra opinião". O texto de Machado, cujo título é "Interesse nacional", foi publicado no dia 27 de maio de 2016, com o objetivo de justamente atentar aos interesses brasileiros envolvidos na questão de um possível "abandono" do Mercosul. O editorial, no entanto, cujo título é "Aproveitar o momento", atenta para as oportunidades que seriam abertas ao Brasil caso este se aproximasse dos grandes acordos comerciais do Norte do globo, liderados principalmente pelos Estados Unidos, como o TTP (sigla em inglês para Parceria Comercial Transpacífica). O jornal reitera que o mundo partiu para a realização de acordos bilaterais, enquanto o Brasil "fi- 
cou preso ao Mercosul, convertido num bunker antiglobalização, portanto reacionário, com a entrada de países como Venezuela, Bolívia e Equador" (O GLOBO, p. 12, 27 mai. 2016). Para Machado, de opinião diversa, é errônea a análise que condena a opção pelo Mercosul, reafirmando que a política adotada por seu partido não é isolacionista, pois foi responsável por um crescimento de $63 \%$ da participação brasileira no mercado mundial. Para o deputado, "a bandeira do livre comércio é pura balela" e o que se busca verdadeiramente com o TPP é "enfraquecer os emergentes e consolidar os interesses geoestratégicos dos EUA" (O GLOBO, p. 12, 27 mai. 2016).

Ao expor dois artigos antagônicos, o jornal elucida ao leitor seus pontos de vista e onde estes se posicionam em relação a correntes contrárias, aqui representadas por Machado. Este, portanto, assume o papel de intelectual da oposição ao jornal, vocalizando neste reduzido espaço as opiniões daqueles contrários a uma brusca mudança no nosso comércio exterior. Pode-se assim classificar Machado como um intelectual orgânico, segundo a noção gramsciana: de origem humilde, ex-agricultor, geógrafo, pertencente aos movimentos sindicalistas, representante de um partido defensor dos direitos do trabalhador, Machado cumpre seu papel de defensor das classes à qual pertence. Digo classes pois não é possível, graças à grande heterogeneidade da sociedade e das disputas ideológicas em que estamos inseridos, colocar agricultores, geógrafos e políticos em um mesmo grupo homogêneo. No entanto, Machado busca representar uma parcela da população que compartilha com ele essa mesma opinião, a qual tende a encontrar mais adeptos nos grupos aos quais ele pertence.

$\mathrm{Na}$ intenção de expor opiniões internacionais que corroborem suas visões, o jornal publica um artigo de Rodrigo Botero Montoya, economista e ex-ministro da Fazenda da Colômbia (1974-1976), colunista do jornal El Colombiano, de Medelín, periódico conhecido por sua defesa de temas conservadores, além de também ser colunista do jornal O Globo ${ }^{4}$. Além disso, seus textos já foram compartilhados nas páginas da revista Veja ${ }^{5}$, também conhecida por seu posicionamento conservador, e no site do $\mathrm{PSDB}^{6}$, partido

4 Em 2011, Montoya já constava na lista de colunistas do jornal. https://oglobo.globo. com/politica/leitores-do-globo-ganham-oito-novos-colunistas-2977632

5 https://veja.abril.com.br/blog/augusto-nunes/rodrigo-botero-montoya-o-pais-imaginario-de-cristina-kirchner/

6 http://www.psdb-rj.org.br/site/midia/artigos/2523-a-igualdade-de-genero-por-rodrigo-botero-montoya 
de defesa das bandeiras neoliberais. Usando como material outros artigos de sua autoria publicados tanto no O Globo quanto no El Colombiano, pode-se afirmar que Montoya se destaca por defender bandeiras liberais e por adotar um posicionamento político mais à direita7. Com isso, além de ser economista e de ter desempenhado importante papel na política colombiana, fica claro o porquê da escolha de seu artigo como meio de exposição da situação do Mercosul ao leitor.

Em artigo publicado em 20 de junho de 2016, Montoya condena o que ele chama de excessivo protecionismo do bloco, e afirma que "os objetivos estritamente comerciais foram obscurecidos por convergências ideológicas e posturas antiocidentais, que se acentuaram com a entrada da Venezuela ao grupo em 2012" (O GLOBO, p. 14, 20 jun. 2016). No texto, cujo título é "As rachaduras do Mercosul", o economista defende que a associação da Venezuela é um fardo diplomático e que sua incorporação se deu "pela porta de trás". O autor ainda se mostra favorável à ideia da ALCA, proposta americana de livre comércio que acabou sendo rechaçada pela maioria dos governos latino-americanos, argumentando que "a aversão a acordos comerciais com os países industrializados levou os presidentes Néstor Kirchner, da Argentina; Lula, do Brasil; e Hugo Chávez, da Venezuela, a rechaçar a proposta americana" (O GLOBO, p. 14, 20 jun. 2016). Dessa forma, seu artigo é claro em se posicionar a favor do alinhamento com os americanos e seus grandes tratados comerciais, defendendo também um Mercosul sem a Venezuela, voltado unicamente ao livre comércio entre seus membros.

Aqui poderiam ser utilizados os argumentos de Schwarz, que argumenta ser impossível a adoção pura de políticas liberais nos trópicos, visto que aqui o capitalismo não chegou a atingir sua forma clássica. As peculiaridades de nossa realidade nos impediriam, portanto, de seguir fielmente um sistema adotado pelo Norte, o que resultaria em anomalias e disfunções. Em outro sentido, pode-se também defender o posicionamento de Montoya a partir dos argumentos de Oliven, segundo o qual as migrações e adaptações das ideias são característica intrínseca à dinâmica cultural, e a interpretação criativa dessas ideias seria um frutífero gerador de novas possibilidades e transformações, o que acaba se convertendo em algo positivo. No entanto, é certo afirmar que Montoya segue a tradição latino-americana de importa-

7 http://www.elcolombiano.com/opinion/columnistas/economia-abierta-y-competitividad-XD7702213 e http://www.elcolombiano.com/opinion/columnistas/nuevo-amanecer-en-argentina-JY7607795 
ção das ideias europeias, e converte-se em mais um intelectual na busca de sua adoção por aqui.

Já no dia 10 de julho de 2016, em comemoração dos vinte e cinco anos de existência do Mercosul, O Globo publica um artigo de autoria de José Serra (PSDB), então ministro das Relações Exteriores do recém iniciado governo Temer. Paulista e filho de imigrantes italianos, Serra tem extensa carreira acadêmica tanto no Brasil quanto no exterior, tendo frequentado instituições renomadas como a Escola Politécnica da USP (embora não tenha se formado por ter de deixar o país em razão do golpe de 1964), Universidade do Chile e Universidade de Princeton (EUA). Também extensa, sua carreira política se inicia quando ainda jovem, sendo eleito presidente da União Nacional dos Estudantes em 1963, tendo participado também da fundação de dois grandes partidos brasileiros: o PMDB, antigo MDB, e o PSDB, partido ao qual é filiado até os dias atuais, e pelo qual disputou suas principais eleições, dentre elas duas à presidência da República (2002/2010). Seu posicionamento político foi de oposição durante todos os governos petistas, e atualmente cumpre o mandato de senador pelo estado de São Paulo ${ }^{8}$.

Em seu artigo, Serra fala na posição de ministro das Relações Exteriores do ainda interino governo Temer, e portanto decide expor suas intenções para com as políticas a serem adotadas futuramente, caso permaneça no cargo. Assim, diz estar determinado "a modernizar o bloco, a derrubar os entraves que ainda impedem o total livre fluxo de comércio dentro do próprio bloco, a negociar matérias pendentes como investimentos e compras governamentais", entre outras propostas que se mostram em sintonia com as opiniões já expostas em editoriais do O Globo. Como outros textos publicados pelo jornal, também questiona a situação venezuelana dentro do bloco, argumentando que sua adesão se deu em "circunstâncias exóticas". Ainda neste mesmo artigo, Serra já menciona uma possível tomada de decisão a respeito do não cumprimento de todas as normas e acordos do bloco por parte dos venezuelanos, prerrogativas fundamentais à completa adesão de qualquer membro. Tal decisão, como já sabemos, seria tomada ao final do ano quando, em dezembro, a Venezuela é suspensa do Mercosul9.

8 http://www.joseserra.com.br/biografia/ e http://www.fgv.br/cpdoc/acervo/dicionarios/verbete-biografico/jose-serra

9 http://www1.folha.uol.com.br/mundo/2016/12/1837650-paises-do-mercosul-assinam-suspensao-da-venezuela-do-bloco.shtml 
Após flertar com os movimentos de esquerda durante as anos 1960, Serra adota para sua vida política um posicionamento muito mais conservador do que aquele que outrora defendera em seus tempos estudantis. Alia-se primeiramente ao então MDB, para depois se deslocar para o PSDB, onde disputou suas principais candidaturas, e onde se alçou a postos como o de prefeito da cidade de São Paulo (2004) e posteriormente governador (2006). Dessa forma, pode-se afirmar que Serra se encaixa no perfil dos chamados intelectuais tradicionais, na concepção gramsciana. Nascido em uma família de classe média baixa, filho de um vendedor de frutas ${ }^{10}$, Serra conseguiu, através dos estudos, ascender socialmente e chegar ao mais alto escalão dos políticos brasileiros. No entanto, abandonou as bandeiras de sua classe de origem (Serra nasceu na Mooca, bairro historicamente de tradição operária de São Paulo), para se alinhar e defender interesses das classes altas, como as privatizações e as impopulares reformas de Temer"1. Seu perfil, portanto, serve de exemplo para dois pontos abordados por Gramsci: primeiramente, o papel da educação como formadora de intelectuais, fato fundamental na trajetória de Serra; segundo, a adesão deste à nova classe à qual se incorporou, passando a defender seus interesses e a trabalhar por sua hegemonia.

A atuação de José Serra como ministro das Relações Exteriores é elogiada em um artigo publicado no mesmo mês, redigido por Denis Lerrer Rosenfield, professor de filosofia da UFRGS, sinalizando a concordância de acadêmicos com a política externa colocada em prática pelo governo Temer. Em exposição bastante didática, o artigo de Rosenfield, intitulado "Diplomacia e democracia", preenche bem a função de difusor de conhecimentos e orientador de interpretações, corroborado pelo prestígio que tem o especialista sobre o leitor. Rosenfield é acadêmico e colunista do jornal O Globo, além de contribuir com outros periódicos e de ser um dos fundadores do Instituto Millenium², cuja linha ideológica é marcada pela defesa de "valores e princípios que garantem uma sociedade livre, como liberdade individual, direito de propriedade, economia de mercado, democracia repre-

10 http://revistaepoca.globo.com/Epoca/0,6993,EPT419866-2011,00.html

11 http://politica.estadao.com.br/noticias/geral,psdb-deve-anunciar-que-permanece-na-base-aliada-de-temer,70001837723

12 https://www.institutomillenium.org.br/author/denisrosenfield/ 
sentativa, Estado de Direito e limites institucionais à ação do governo"13. Se destaca pela forte defesa das liberdades individuais e pela crítica à intervenção do Estado, mesmo em casos de bem comum como a proibição do fumo em locais fechados ${ }^{14}$. Assim, tem se consolidado como um grande crítico dos governos petistas, e suas opiniões encontram adeptos principalmente em grupos de direita. Com esse histórico, são inúmeros os artigos em que trata da questão venezuelana, onde condena fortemente as ações dos governos Chávez e Maduro15.

Como acadêmico, seu artigo carrega a intenção de oferecer ao público uma explicação sobre o contexto histórico dos países membros, ao lado da evolução das doutrinas de esquerda que serviram de orientação a vários chefes de Estado da região. Ainda sobre a questão daquele momento, a situação da Venezuela, Rosenfield ergue uma retrospectiva dos principais atos da história recente daquele país, ambientando o leitor leigo sobre o debate dentro do bloco, ainda explicitando os motivos deste ser importante "porque diz respeito ao que esse governo e o anterior consideram como democracia". Traça logo uma diferenciação entre as atitudes de Dilma e Temer, explicitando que o segundo "está recolocando a questão em sua verdadeira dimensão, rompendo decisivamente com essa orientação ideológica" ( $O$ GLOBO, p. 12, 11 jul. 2016), enaltecendo Temer por buscar o bem da nação. Assim, alerta o leitor de que este está diante de uma discussão plena de significados, os quais ele introduz em seu artigo na intenção de oferecer um guia aos imperitos no assunto. Rosenfield poderia ser descrito, segundo a classificação de Bobbio, como um intelectual ideólogo, isto é, um fornecedor de princípios-guia para seus leitores, o que encaixa com sua formação na filosofia. Seu papel como intelectual aqui se exerce no sentido de orientar o leitor acerca dos termos desse debate, oferecendo assim a opinião do estudioso, do perito, acerca de um assunto um tanto quanto distante da realidade da maior parte da população. Assim, o artigo de Rosenfield cumpre o papel social do texto opinativo, de guia de interpretações e compreensões sobre o mundo ao nosso redor (MONT'ALVERNE, MARQUES, 2015).

13 https://www.institutomillenium.org.br/institucional/quem-somos/

14 https://www.institutomillenium.org.br/divulgacao/a-anvisa-se-autoconsagrou-grande-tutor-brasileiro-diz-denis-rosenfield/

15 http://opiniao.estadao.com.br/noticias/geral,a-democracia-totalitaria-bolivariana,70001943717 e https://www.institutomillenium.org.br/artigos/democracia-ditadura/ 


\section{CONSIDERAÇÕES}

A partir da revisão bibliográfica de alguns dos principais autores quando se aborda o tema dos intelectuais, foi possível fazer uma breve análise sobre as diferentes definições e ensaios sobre tal ofício. É certo que, quando se aborda um grupo de pessoas que possuem uma mesma ocupação, há sempre a tentativa de classificar tal grupo e posicioná-lo em relação aos demais grupos da sociedade, buscando sempre referenciá-los pelas semelhanças ou diferenças que possuem entre si e com os demais cidadãos. Aqui, buscamos analisar exatamente suas diferenças, isto é, o que estas personalidades selecionadas por O Globo têm de específico para serem porta vozes dos interesses das classes às quais pertencem.

A partir da análise de seus perfis profissionais e pessoais (dentro do material disponível para pesquisa), foi possível traçar o tipo intelectual ao qual correspondem, seja ele do tipo orgânico, segundo a análise gramsciana, ou ideólogo, seguindo a classificação dada por Bobbio. Os estudos dos autores aqui citados foram fundamentais para auxiliar na compreensão do papel dos intelectuais no Brasil de hoje, seja a partir das conceituações de cunho teórico, seja através da narrativa acerca do seu papel ao longo da história. A posição dos intelectuais na sociedade de hoje se deve muito às contribuições de seus precursores e também às condições políticas em que nos encontramos atualmente, as quais têm possibilitado o alargamento e a valorização de seu ofício, assim como têm se ampliado os espaços e as oportunidades abertas a esse grupo.

Portanto, uma das maiores afirmações que saem desse trabalho é a de que a atividade intelectual, assim como os temas abordados por esta, são historicamente determinados, e sofrem influências das lutas sociais em que estão inseridas. Assim, ao analisar a trajetória de nomes como os de José Serra e Sibá Machado, por exemplo, foi possível perceber como o caminho que percorreram em suas vidas privadas e públicas foi determinante para a escolha das causas que defendem. Dito isto, cabe ressaltar também o papel que cumprem a redemocratização e a liberdade dos periódicos, os quais são de extrema importância para que tais vozes possam ter espaço para vocalizar os interesses de seus grupos, fazendo com que estas ideias repercutam na sociedade, gerando não só debates, mas também mudanças e avanços. Sendo assim, o presente trabalho busca ressaltar a importância do intelectual não somente nesse caso específico aqui exposto, mas principalmente 
sua importância no curso da história, a qual envolve e é envolvida por esse ofício.

\begin{abstract}
E por isso mesmo os intelectuais de hoje devem muitas de suas características às transformações institucionais em que estiveram envolvidos esses precursores, ampliando o espaço de autonomia em que operamos, forjando as imagens conflitantes que temos a respeito de nossa condição social e fazendo ver os limites que pesam sobre nossa contribuição (MICELI, 1979, p. 197)
\end{abstract}

\title{
REFERÊNCIAS
}

BOBBIO, Noberto. Os intelectuais e o poder: dúvidas e opções dos homens de cultura na sociedade contemporânea. Tradução de Marco Aurélio Nogueira. São Paulo: Editora UNESP, 1997.

GRAMSCI, Antônio. Os intelectuais. O princípio educativo. Jornalismo. Cadernos do cárcere - $2^{\mathrm{a}}$ ed. - Rio de Janeiro: Civilização Brasileira, 2001.

MICELI, Sérgio. Intelectuais e classe dirigente no Brasil (1920-1945). São Paulo: Difel, 1979. MONT'ALVERNE, Camila; MARQUES, Francisco Paulo Jamil. A opinião da empresa no Jornalismo Brasileiro: um estudo sobre a função e a influência política dos editoriais. Florianópolis: Estudos em Jornalismo e Mídia, 2015, vol. 12, no 1.

O GLOBO. Acervo digitalizado. Disponível em < http://acervo.oglobo.globo.com >. Acesso em 09 jan 2018.

OLIVEN, Ruben George. Cultura e modernidade no Brasil. São Paulo em Perspectiva, v. 15, n. 2, p. 3-12, 2001.

SCHWARZ, Roberto. As ideias fora do lugar: ensaios selecionados. São Paulo: Penguin Classics Companhia das Letras, 2014. 


\section{Thaís Manhães Alves Soares}

Gadruada em Relações Internacionais pela Universidade Federal do Rio de Janeiro e mestranda do Programa de Pós-Graduação em Comunicação da Universidade Federal de Juiz de Fora (PPGCOM/UFJF), linha de pesquisa Comunicação e Poder, no estado de Minas Gerais.

E-mail: thaismanhaesalves@gmail.com

\section{Paulo Roberto Figueira Leal}

Professor doutor da Faculdade de Comunicação da Universidade Federal de Juiz de Fora (FACOM/UFJF) e do Programa de Pós-Graduação em Comunicação da Universidade Federal de Juiz de Fora (PPGCOM/UFJF), no estado de Minas Gerais. E-mail: pabeto.figueira@uol.com.br 